medicareehrprogram_pqrs_erxcomparison.pdf. Accessed September 26, 2015.

3. Centers for Medicare \& Medicaid Services. Electronic health records (EHR) incentive programs. October 29, 2015. Available from: https://www.cms.gov/Regulations-and-Guidance/ Legislation/EHRIncentivePrograms/index.html? redirect =/ ehrincentiveprograms. Accessed September 26, 2015.

4. Blue perspective. Value-based programs. Washington, DC: BlueCross BlueShield Association; 2014. Available from: http:// www.bcbs.com/healthcare-news/press-center/BP-and-Qualityand-Plan-Innovations.pdf. Accessed September 26, 2015.

5. Institute of Medicine. Crossing the quality chasm: a new health system for the 21st century. March 2001. Available from: https://iom.nationalacademies.org/ /media/Files/ Report\%20Files/2001/Crossing-the-Quality-Chasm/ Quality\%20Chasm\%202001\%20\%20report\%20brief.pdf. Accessed November 18, 2015.

doi: 10.3122/jabfm.2016.01.150320

\section{Re: Clinical Decisions Made in Primary Care Clinics Before and After Choosing Wisely ${ }^{\mathrm{TM}}$}

To the Editor: Kost and Genoa demonstrated that physician adherence to guidelines for 5 low-value clinical decisions improved through educational interventions. ${ }^{1}$ They concluded that "primary care physicians respond to training and publicity in low-value care." This intervention strategy decreased physician-initiated testing that provide little clinical value. In this way, the Choosing Wisely initiative may help to achieve the health care triple aim. ${ }^{2}$ However, the authors failed to explain why there were drastic differences in responses among the intervention groups. Of the 5 clinical decisions that were targeted, 2 groups (antibiotics for acute sinusitis, dualenergy X-ray absorptiometry for osteoporosis screening) improved in adherence markedly, and 3 groups (cervical cancer screening, heart disease screening, back pain imaging) did not change significantly. This disparity merits thoughtful discussion and a call for further research.

The authors propose that the groups showing no improvement shared very high adherence before the intervention, "limiting the opportunity for change." This is one plausible explanation for the lack of improvement in these 3 groups. However, there are numerous other possible explanations for the difference in improvement. Perhaps different clinical decision groups were subjected to different interventions, and thus produced different results. The article states that groups were provided with an in-person seminar or a webinar, but does not reveal which groups had each intervention. Active learning is superior to lecture for learner retention. ${ }^{3}$ If the groups that improved were given the webinar, this could account for their change. The difference may also be explained by confounding variables. Avoiding certain low-value decisions may have been reinforced outside of the study. Billboards, posters, or other resident lectures may have given publicity to the lack of value in giving antibiotics for sinusitis, for example. If residents were not exposed to similar materials on back pain, this inequality could have caused the differences found by the authors. Examining every possible reason for the difference may not have been within the authors' intent. However, the identification of different responses to their intervention strategy is important. It is a loss to allow the difference to disappear by averaging all 5 groups together.

The goal of the Choosing Wisely initiative is to expose clinical decisions whose necessity should be questioned or discussed. ${ }^{4}$ This article clearly highlights one way to help reach the initiative's goal. It shows that physicians respond to education regarding certain clinical decisions. However, it just as clearly shows that some low-value decisions did not change as a result of educational interventions. To achieve the health care triple aim, we must discover interventions that will help physicians avoid low-value testing. We cannot reach this ideal without thoughtful examination of both successful and unsuccessful interventions for low-value decisions.

Joseph B. Gladwell, MD

Riverside Family Medicine Residency

Columbus, $\mathrm{OH}$

Joseph.Gladwell@ohiohealth.com

\section{References}

1. Kost A, Genao I, Lee JW, Smith SR. Clinical decisions made in primary care clinics before and after Choosing Wisely. J Am Board Fam Med 2015;28:471-4.

2. IHI triple aim initiative. Cambridge, MA: Institute for Healthcare Improvement. Available from: http://www.ihi. org/engage/initiatives/tripleaim. Accessed August 28, 2015.

3. Mains TE, Cofranscesco J, Milner SM, Shah NG, Goldberg $\mathrm{H}$. The impact of audience response systems on medical student learning. Postgrad Med J 2015;91:361-7.

4. Choosing Wisely [homepage]. Philadelphia: ABIM Foundation. c2015. Available from: www.choosingwisely.org. Accessed August 28, 2015.

doi: 10.3122/jabfm.2016.01.150287

The above letter was referred to the authors of the article in question, who offer the following reply.

\section{Response: Re: Clinical Decisions Made in Primary Care Clinics Before and After Choosing Wisely ${ }^{\mathrm{TM}}$}

To the Editor: We thank Dr. Gladwell for his thoughtful comments regarding our article about the impact of the Choosing Wisely campaign on clinical decisions made in primary care clinics. As he notes, achieving value in health care is a critical component of improving our health care system. Thus it is necessary to know what kinds of interventions might be successful at increasing the rates of high-value care.

Space limitations precluded a full discussion of limitations in our study, so we welcome Dr. Gladwell's elaboration of the known limitations of the quasi-experimental design we used. Clinics were not randomly assigned, and all received the educational intervention and exposure to the launch of the Choosing Wisely campaign. We agree that it is not possible to quantify all potential aspects of this exposure. The launch of the Choosing 